\title{
Front Matter: Volume 6624
}

, "Front Matter: Volume 6624," Proc. SPIE 6624, International Symposium on Photoelectronic Detection and Imaging 2007: Optoelectronic System Design, Manufacturing, and Testing, 662401 (12 March 2008); doi: 10.1117/12.792915

SDIE Event: International Symposium on Photoelectronic Detection and Imaging: Technology and Applications 2007, 2007, Beijing, China 


\title{
PROCEEDINGS OF SPIE
}

\section{International Symposium on Photoelectronic Detection and Imaging 2007 \\ Optoelectronic System Design, Manufacturing, and Testing}

\author{
Liwei Zhou \\ Chair/Editor
}

9-12 September 2007

Beijing, China

Organized by

Topical Committee of Optics, China Ordnance Society (China)

School of Information and Technology, Beijing Institute of Technology (China)

The Editorial Office of Optical Technique (China)

Sponsored by

China Ordnance Society (China)

Beijing Institute of Technology (China)

Cooperating Organization

SPIE

Supported by

North Night Vision Technology Company, Ltd. (China) • Kunming Institute of Physics (China) • Beijing Weisidun Asia Pacific Technology Company, Ltd. (China) • The 8358th Institute of 3rd Research Academy, CASIC

(China)

Chinese Society of Astronautics (China) • Hamamatsu Photonics K.K. (Japan) • Topical Committee of OptoElectronic Technology, Chinese Optical Society (China) • Beijing Optical Society (China) • The 205th Institute of China Ordnance Industry Corporation Group (China)

Published by

SPIE

Volume 6624

Proceedings of SPIE, 0277-786X, v. 6624 
The papers included in this volume were part of the technical conference cited on the cover and title page. Papers were selected and subject to review by the editors and conference program committee. Some conference presentations may not be available for publication. The papers published in these proceedings reflect the work and thoughts of the authors and are published herein as submitted. The publisher is not responsible for the validity of the information or for any outcomes resulting from reliance thereon.

Please use the following format to cite material from this book:

Author(s), "Title of Paper," in International Symposium on Photoelectronic Detection and Imaging 2007: Optoelectronic System Design, Manufacturing, and Testing, edited by Liwei Zhou, Proceedings of SPIE Vol. 6624 (SPIE, Bellingham, WA, 2008) Article CID Number.

ISSN 0277-786X

ISBN 9780819467669

Published by

SPIE

P.O. Box 10, Bellingham, Washington 98227-0010 USA

Telephone +1 3606763290 (Pacific Time) · Fax +1 3606471445

SPIE.org

Copyright (c) 2008, Society of Photo-Optical Instrumentation Engineers

Copying of material in this book for internal or personal use, or for the internal or personal use of specific clients, beyond the fair use provisions granted by the U.S. Copyright Law is authorized by SPIE subject to payment of copying fees. The Transactional Reporting Service base fee for this volume is $\$ 18.00$ per article (or portion thereof), which should be paid directly to the Copyright Clearance Center (CCC), 222 Rosewood Drive, Danvers, MA 01923. Payment may also be made electronically through CCC Online at copyright.com. Other copying for republication, resale, advertising or promotion, or any form of systematic or multiple reproduction of any material in this book is prohibited except with permission in writing from the publisher. The CCC fee code is 0277-786X/08/\$18.00.

Printed in China.

Publication of record for individual papers is online in the SPIE Digital Library.

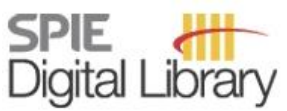

SPIEDigitalLibrary.org

Paper Numbering: Proceedings of SPIE follow an e-First publication model, with papers published first online and then in print and on CD-ROM. Papers are published as they are submitted and meet publication criteria. A unique, consistent, permanent citation identifier (CID) number is assigned to each article at the time of the first publication. Utilization of CIDs allows articles to be fully citable as soon they are published online, and connects the same identifier to all online, print, and electronic versions of the publication. SPIE uses a six-digit CID article numbering system in which:

- The first four digits correspond to the SPIE volume number.

- The last two digits indicate publication order within the volume using a Base 36 numbering system employing both numerals and letters. These two-number sets start with $00,01,02,03,04,05$, 06, 07, 08, 09, OA, OB ... 0Z, followed by 10-1Z, 20-2Z, etc.

The CID number appears on each page of the manuscript. The complete citation is used on the first page, and an abbreviated version on subsequent pages. Numbers in the index correspond to the last two digits of the six-digit CID number. 


\section{Contents}

$\begin{array}{ll}x i & \text { Symposium Committees } \\ x \vee & \text { Introduction }\end{array}$

662402 Simultaneous 360 degree viewing optical system with the lenses of the compound eyes from the dragonfly [6624-01]

S.-W. Kim, R. S. Ramakrishna, Gwangju Institute of Science and Technology (South Korea)

$662403 \quad$ Evaluating the viscoelastic properties of glass above transition temperature for numerical modeling of lens molding process [6624-02]

T. Zhou, J. Yan, T. Kuriyagawa, Tohoku Univ. (Japan)

662404 Cobalt chloride doped polymer film for relative humidity measurement [6624-03]

P. Nath, M. Datta, A. Barik, A. Ali, H. K. Singh, Gauhati Univ. (India); A. K. Kalita, Assam

Engineering College (India); P. Datta, Gauhati Univ. (India)

662405 Preexposure effect on the fabrication of continuous relief microstructure and advanced method [6624-04]

D. Wang, C. Luo, H. Liu, Z. Ye, Lanzhou Institute of Physics (China)

662406 Research on the NO gas-sensitive effect of long-period fiber gratings coated with film [6624-05]

Y. Peng, M. Sun, Dalian Univ. of Technology (China) and Dalian Maritime Univ. (China)

662407 The optimization of incoherent fiber laser beam combination [6624-06]

J. Xu, S. Zhao, S. Zhan, R. Hou, J. Wu, Y. Li, S. Fang, Air Force Engineering Univ. (China)

662408 Laser diode transmitter for laser radar based on FM ranging principles [6624-07]

W. Yang, J. Zhao, X. Du, Z. Zeng, Q. Wang, The Academy of Equipment Command \& Technology (China)

662409 The fractal character of micromirror for metal MEMS optical switch [6624-08]

Y. Zhang, Y. Luo, X. Xu, Chongqing Univ. of Posts and Telecommunications (China)

$66240 \mathrm{~A}$ Annular sub-aperture stitching interferometry for testing of large aspherical surfaces [6624-09]

X. Wang, L. Wang, Changchun Institute of Optics, Fine Mechanics and Physics (China) and Graduate School of the Chinese Academy of Sciences (China); L. Zheng, Changchun Institute of Optics, Fine Mechanics and Physics (China); W. Deng, Changchun Institute of Optics, Fine Mechanics and Physics (China) and Graduate School of the Chinese Academy of Sciences (China); X. Zhang, Changchun Institute of Optics, Fine Mechanics and Physics (China)

$6624 \mathrm{OB}$ Effect of gaps and piston on image quality for large segmented telescope [6624-10] J. Yan, Y. Wen, X. YU, X. Zhang, Beijing Institute of Technology (China) 
6624 OC Study on optical design of all-reflective Fourier transform imaging spectrometer [6624-11] M. Liang, N. Liao, Beijing Institute of Technology (China)

6624 OD Testing the large aperture optical components by the sub-aperture stitching interferometer [6624-12]

Y. He, Z. Wang, Q. Wang, B. Ji, Nanjing Univ. of Science \& Technology (China)

6624 OE Studies on LSPR effect of assembled gold nanoparticles film [6624-13]

D. Du, X. Hong, Tianjin Univ. (China)

6624 OF A new method of realizing the super light space zoom reflector [6624-14]

K. Tao, S. Fu, X. Qu, B. Sun, Y. Zhou, Harbin Institute of Technology (China)

6624 OG Optical measuring system for defects of artillery lumen [6624-15]

W. Zhu, C. Xu, D. Xiao, Beijing Institute of Technology (China)

$6624 \mathrm{OH} \quad$ Study on the polarization dependency of diffraction efficiency of perfectly conducting blazed gratings [6624-16]

S. Li, T. Tang, J. Zhu, Xi'an Jiaotong Univ. (China)

6624 Ol Design and research of zoom optic system applied in micro-processing using 248nm KrF excimer laser [6624-17]

X. Liu, T. Chen, T. Zuo, Beijing Univ. of Technology (China)

$6624 \mathrm{OJ}$ The theoretical and experimental research on endoscopic confocal imaging system [6624-18]

H. Ge, Donghua Univ. (China); B. Wang, Shanghai Univ. (China); Q. Ren, Shanghai Jiaotong Univ. (China)

6624 OK New design techniques and alignment methods for CGH-null testing of aspheric surface [6624-19]

G. Kang, J. Xie, Beijing Institute of Technology (China); Y. Liu, China Precision Engineering Institute for Aircraft Industry (China)

$6624 \mathrm{OL}$ Methodology on zoom system design and optimization [6624-20]

Q. Ding, H. Liu, Luoyang Institute of Electro-optical Equipment (China)

6624 OM Research and application of ergonomics to optical microscope [6624-21]

X. Jiang, Z. Xiao, J. Zhang, Guilin Univ. of Electronic Technology (China)

6624 ON New method for detecting the piston of segmented mirrors: a modification of the peak ratio technique [6624-22]

D. QU, Y. Zhao, L. Dong, R. Chen, Beijing Institute of Technology (China)

662400 Sampling pulses with symmetric Mach-Zehnder interferometer optical switch [6624-23]

Y. Yang, Z. Zheng, Z. Li, Beijing Univ. of Aeronautics and Astronautics (China)

6624 OP Performance analysis of Brillouin optical time domain reflectometer using Golay

complementary sequence [6624-24]

X. Cheng, Y. Li, North China Electric Power Univ. (China) 
$6624 \mathrm{OQ}$ Estimation of the measurement uncertainty based on quasi Monte-Carlo method in optical measurement [6624-25]

H. Jing, M. Huang, Y. Zhong, B. Kuang, Guilin Univ. of Electronic Technology (China);

$X$. Jiang, Huazhong Univ. of Science and Technology (China)

6624 OR Golay3 sparse aperture systems designed on a spherical surface [6624-26]

F. Wu, Soochow Univ. (China) and Changzhou Institute of Technology (China); Q. Wu, Soochow Univ. (China) and Univ. of Science and Technology of Suzhou (China); L. Qian, Soochow Univ. (China)

6624 OS Application of conformal optical design in star sensor [6624-27]

Y. Li, L. Li, Y. Huang, J. Liu, Beijing Institute of Technology (China)

6624 OT Analysis on the interferogram of a low coherence interferometric system for measuring the dispersion of chirped fiber grating through Fourier spectrometry method [6624-28]

Q. Chen, Beijing Univ. of Posts and Telecommunications (China) and Beijing Institute of Machinery (China); N. Lu, Beijing Institute of Machinery (China); X. Sang, Beijing Univ. of Posts and Telecommunications (China)

6624 OU Research of the application of low-precision large aperture nonimaging optics in freespace optical communication system [6624-29]

J. Wang, Beijing Institute of Graphic Communication (China); X. Yu, Beijing Institute of Technology (China)

6624 OV Designed achromatic quarter wave plates of subwavelength grating structure [6624-30] J. Zhang, S. Yan, C. Zhou, S. Shen, E. Li, H. Tong, National Univ. of Defense Technology (China)

6624 OW Design of multi-layer diffractive lenses to correct secondary spectrum [6624-31] $\mathrm{H}$. Xing, Institute of Optics and Electronics (China) and Graduate School of the Chinese Academy of Sciences (China); W. Lin, Institute of Optics and Electronics (China); J. Feng, Z. Liao, Institute of Optics and Electronics (China) and Graduate School of the Chinese Academy of Sciences (China)

$66240 X$ Image based measurement for the center position error of micro-sphere in micro-target [6624-32]

T. Wang, Z. Qiu, J. Wang, B. Wang, Tianjin Univ. (China)

6624 OY Polarization aberrations caused by fold mirrors in optical systems [6624-33]

Y. Zhang, Beihang Univ. (China); L. Li, Beijing Institute of Technology (China); H. Zhao, Beihang Univ. (China)

$66240 Z$ Design of the scanning mode coated glass color difference online detection system [6624-34]

W. Bi, Y. Zhang, D. Wang, B. Zhang, G. Fu, Yanshan Univ. (China)

662410 Beaming of light from metallic surface plasmon polaritons nanostructure [6624-35]

G. Zhang, J. Liu, C. Hu, F. Sun, X. Su, Beijing Jiaotong Univ. (China) 
662411 A combination of BIM and BEM for efficiently analyzing optical elements [6624-36] F. Sun, J. Liu, G. Zhang, C. Hu, X. Su, Beijing Jiaotong Univ. (China)

662412 A novel algorithm of wave front time domain testing [6624-37] L. Tang, Q. Hao, Q. Zhu, Beijing Institute of Technology (China)

$662413 \quad \mathrm{ZnO} / \mathrm{Ag} / \mathrm{ZnO}$ multilayer films deposited at room temperature [6624-38] J. Yan, X. Sun, Y. Zhu, Y. Zhao, Ludong Univ. (China)

662414 A convertible aerial camera system integrated with film and CCD image sensor [6624-39] L. Yan, S. Zhao, Peking Univ. (China); Z. Lian, Peking Univ. (China) and Beihang Univ. (China)

662415 Fiber point diffraction interferometer in measurement of spherical lens [6624-40] S. Wu, T. Zhou, J. Lin, L. Chen, L. Nie, D. Sha, Beijing Institute of Technology (China)

662416 Design of a compact wide field of view HMD optical system using freeform surfaces [6624-41]

M. M. Talha, Y. Wang, D. Cheng, J. Chang, Beijing Institute of Technology (China)

662417 Form error automatic measurement system based on optical fiber sensing array [6624-42] S. Jin, Y. Lv, Q. S. Chen, Beijing Institute of Machinery (China)

662418 Closed loop high precision position control system with optical scale [6624-43] C. Ge, Univ. of Electric and Scientific Technology of China (China) and Institute of Applied Electronics, China Academy of Engineering Physics (China); Y. Liao, Z. He, Z. Luo, Z. Huang, M. Wan, X. Hu, G. Fan, Institute of Applied Electronics, China Academy of Engineering Physics (China); Z. Liang, Univ. of Electric and Scientific Technology of China (China)

662419 Analyses of test glass edge-effect on coatings monitoring [6624-44] H. Wang, J. Heng, W. Lu, X. Li, W. Xue, Beijing Institute of Technology (China)

6624 IA Ion beam sputter deposition of zirconia thin films [6624-45] W. Jin, Changchun Institute of Optics, Fine Mechanics and Physics (China) and Graduate School of the Chinese Academy of Sciences (China); C. Jin, Changchun Institute of Optics, Fine Mechanics and Physics (China); L. Liu, H. Zhu, Changchun Institute of Optics, Fine Mechanics and Physics (China) and Graduate School of the Chinese Academy of Sciences (China); H. Yang, Changchun Institute of Optics, Fine Mechanics and Physics (China)

6624 1B Optical characteristic of ion beam sputter deposited aluminum thin films [6624-46] W. Jin, Changchun Institute of Optics, Fine Mechanics and Physics (China) and Graduate School of the Chinese Academy of Sciences (China); C. Jin, Changchun Institute of Optics, Fine Mechanics and Physics (China); H. Zhu, L. Liu, Changchun Institute of Optics, Fine Mechanics and Physics (China) and Graduate School of the Chinese Academy of Sciences (China); H. Yang, Changchun Institute of Optics, Fine Mechanics and Physics (China)

6624 1C Design of absorbency photometer used in a fully automatic ELISA analyzer [6624-47] N. Dong, L. Zhu, M. Dong, Beijing Institute of Machinery (China); S. Niu, Beijing Success Technology Co. Ltd. (China) 
6624 ID Fisheye supplementary lens for liquid crystal projector [6624-48]

Z. Jiang, L. Li, Y. Huang, Beijing Institute of Technology (China)

$66241 \mathrm{E}$ A novel verification device for optical aiming equipments [6624-49]

Z. Zhu, X. Guo, H. Ding, L. Ding, Xi' an Research Institute of High Technology (China)

6624 IF Optimization control based on hierarchical coordination for a space-based telescope [6624-50]

B. Guo, Z. Liu, Beijing Institute of Technology (China)

$66241 \mathrm{G}$ The measurement and system error analysis of diopter and optical parallax in optical pointing system [6624-51]

W. Cao, C. Xue, L. Li, Z. An, Changchun Univ. of Science and Technology (China)

$66241 \mathrm{H}$ The research for EO imaging system simulation [6624-52]

H. Yang, Nankai Univ. (China); L. Wang, Changchun Institute of Optics, Fine Mechanics and Physics (China) and Graduate School of Chinese Academy of Sciences (China);

Z. Fang, Nankai Univ. (China); J. Zhang, Changchun Institute of Optics, Fine Mechanics and Physics (China) and Graduate School of Chinese Academy of Sciences (China);

X. Zhang, Changchun Institute of Optics, Fine Mechanics and Physics (China)

662411 Application of a high-precision interferometric measuring system as phasing the segmented primary mirrors of the next generation of ground-based telescope [6624-53] H. Song, Institute of Optics and Electronics (China) and Graduate School of Chinese Academy of Sciences (China); H. Xian, W. Jiang, C. Rao, Institute of Optics and Electronics (China); J. Huang, Institute of Optics and Electronics (China) and Graduate School of Chinese Academy of Sciences (China)

$66241 \mathrm{~J}$ A binary beam-splitter for lidar beam-shaping in laser imaging application [6624-54] G. Zheng, S. Li, H. Zhou, Wuhan Univ. (China)

6624 IK Design of an inflatable and deployable space reflecting concentrator [6624-55] B. Wang, Z. Yang, B. Mao, T. Zhang, Y. Feng, Beijing Institute of Technology (China)

$66241 \mathrm{~L}$ Optical properties of porous anodic alumina films implanted with ZnO nanoparticles [6624-56]

J. Yan, X. Sun, Y. Zhu, Y. Zhao, Ludong Univ. (China)

$66241 \mathrm{M}$ Hybrid phase-diverse phase retrieval algorithm in wavefront sensing for segmented optics [6624-57]

H. Mao, X. Wang, D. Zhao, Beijing Institute of Technology (China)

$66241 \mathrm{~N}$ Summarize of conformal optics [6624-58]

N. Zhao, J. Chang, Z. Sun, Y. Wang, Beijing Institute of Technology (China)

662410 The preparation of AZO films with RF sputtering [6624-59]

Z. Yu, J. Xu, W. Xue, X. Li, J. Li, Beijing Institute of Technology (China)

6624 IP The effects of process parameters on the properties of ITO films grown by ion beamassisted deposition using $90 \mathrm{In}-10 \mathrm{Sn}$ (wt\%) alloy [6624-60]

Z. Yu, L. Xiang, W. Xue, H. Wang, W. Lu, Beijing Institute of Technology (China) 
$66241 Q$ An integrated measurement system for LED thermal, optical, and electrical characteristics [6624-61]

X. Zou, China Jiliang Univ. (China); X. Zheng, Starspec Optoelectronic Technology Co., Ltd. (China); S. Jin, K. Ni, China Jiliang Univ. (China); H. Zhou, X. He, Starspec Optoelectronic Technology Co., Ltd. (China)

6624 IR Characteristics of the photoinduced current pulses of the optically addressed photorefractive BSO spatial light modulators [6624-62]

X. Li, W. Hu, H. Jia, J. Zhang, J. Yang, National Univ. of Defense Technology (China)

6624 iS Design of a three field-of-view IR system [6624-63]

J. Chang, Beijing Institute of Technology (China); Z. Weng, Changchun Institute of Optics, Fine Mechanics and Physics (China); Y. Wang, Beijing Institute of Technology (China); $\mathrm{H}$. Jiang, Changchun Univ. of Science and Technology (China); X. Cong, Changchun Institute of Optics, Fine Mechanics and Physics (China)

6624 1T Compressed infrared mirror-lens system design [6624-64]

T. Ren, Changchun Univ. of Science and Technology (China); J. Chang, Beijing Institute of Technology (China); Z. Weng, Changchun Institute of Optics, Fine Mechanics and Physics (China); H. Jiang, Changchun Univ. of Science and Technology (China); X. Cong,

Changchun Institute of Optics, Fine Mechanics and Physics (China)

$66241 \mathrm{U}$ Superprism structure with linear spatial dispersion based on thin film Gires-Tournois cavity [6624-65]

W. Lv, D. Zhang, J. Chen, Univ. of Shanghai for Science and Technology (China)

6624 IV Computer-aided alignment for the segmented mirrors of three-mirror optical system [6624-66]

Y. Huang, L. Li, Beijing Institute of Technology (China)

$66241 \mathrm{~W} \quad$ Research on blue emitting $\mathrm{BaAl}_{2} \mathrm{~S}_{4}$ : Eu phosphor layers of TFEL [6624-67]

Z. Ding, Z. Yu, W. Xue, Beijing Institute of Technology (China)

$66241 \mathrm{X}$ Study on the laser beam transformation and its measurement in laser processing [6624-68] R. Ye, Y. Huang, Z. Weng, T. Hu, S. Lin, H. Yan, Z. Wu, Xiamen Univ. (China)

6624 IY Study of wavefront error and polarization of a side mounted infrared window [6624-69] J. Liu, L. Li, X. Hu, X. Yu, Beijing Institute of Technology (China)

662412 Application of virtual optical assembly in research and development of special optical instrument [6624-70]

Z. Xiao, Z. Sun, Guilin Univ. of Electronic Technology (China)

662420 Optical design of a confocal scanning laser ophthalmoscope based on adaptive optics [6624-71]

J. Lu, Y. Zhang, X. Rao, G. Shi, H. Yang, C. Wang, Institute of Optics and Electronics (China)

662421 Contamination effects of oil paint on the space optical system [6624-72]

C. Lu, Y. Zhou, Y. Sang, Harbin Institute of Technology (China) 
662422 The design of the CMOS wireless barcode scanner applying optical system based on ZigBee [6624-73]

Y. Chen, J. Peng, Guilin Univ. of Electronic Technology (China)

662423 Design of optical elements for imaging the Earth's plasmasphere [6624-74]

L. Wang, X. Wang, Changchun Institute of Optics, Fine Mechanics and Physics (China) and Graduate School of Chinese Academy of Sciences (China); B. Chen, Changchun Institute of Optics, Fine Mechanics and Physics (China)

662424 Antireflection coatings of broad angle range for ultraviolet band designed by rugate coatings [6624-75]

G. Peng, J. Yang, S. Chang, H. Yin, J. Yang, National Univ. of Defense Technology (China)

662425 Influence of the size dispersion on the emission spectra of the hydrogen passivated $\mathrm{Si}$ nanoparticles in SiNx [6624-76]

W. Ding, Z. Hao, W. YU, J. Zhang, Y. Li, G. Fu, Hebei Univ. (China)

662426 Influence of hydrogen dilution on bonding configurations and optical absorption properties of a-Si/SiNx composite films [6624-77]

W. YU, Y. Li, W. Ding, J. Zhang, Y. Yang, G. Fu, Hebei Univ. (China)

Author Index 
Downloaded From: https://www.spiedigitallibrary.org/conference-proceedings-of-spie on 26 Apr 2023

Terms of Use: https://www.spiedigitallibrary.org/terms-of-use 


\title{
Symposium Committees
}

\author{
Honorary Chair \\ Wang Daheng, Chinese Academy of Sciences (China) \\ General Chairs \\ Zhou Liwei, Beijing Institute of Technology (China) \\ Jin Guofan, Tsinghua University (China) \\ Wang Dechen, China Ordnance Society (China) \\ Kuang Jingming, Beijing Institute of Technology (China) \\ Jiao Wenjun, Beijing Institute of Technology (China) \\ Advisory Committee \\ Zhou Bingkun, Tsinghua University (China) \\ Mu Guoguang, Nankai University (China) \\ Qin Yuwen, National Natural Science Foundation Committee \\ (China) \\ Yin Xingliang, General Manager of CASIC (China) \\ Hou Xun, Xi' an Institute of Optics and Fine Mechanics (China) \\ Francis T.S.Yu, University of Pennsylvania (USA) \\ Teruo Hiruma, Hamamatsu Photonics K.K. ( Japan) \\ M. Ya. Schelev, Physics Institute, Russia Academy of Sciences \\ (Russia) \\ V. Soifer, Samara State Aerospace University (Russia) \\ Feng Changgen, China Association for Science and Technology \\ (China) \\ Huang Shanglian, Chongqing University (China) \\ Horst Weber, Berlin Technical University (Germany) \\ Igor D. Burlakov, Federal State Unitary Enterprise ORION (Russia) \\ Organizing Committee \\ Chairs \\ Yu Xin, Beijing Institute of Technology (China) \\ Qi Kangnan, Beijing Optical Society (China) \\ Xu Yida, China Ordnance Society (China) \\ Members \\ Zhang Yimo, Tianjin University (China) \\ Deng Shushen, Beijing Optical Society (China) \\ Cui Yuping, The 8358th Institute of CASIC (China) \\ Yoshui Suzuki, Hamamatsu Photonics K.K. (Japan)
}


Zhao Yuejin, Topical Committee of Optics, China Ordnance Society (China)

Gu Ying, Beijing 301 Hospital (China)

Wang Xiaopeng, The 205th Institute of China Ordnance Industry Corporation Group (China)

Zeng Guilin, North Night Vision Technology Company, Ltd. (China)

Liu Xiaohua, Beijing Weisidun Asia Pacific Technology

Company, Ltd. (China)

Program Committee

Chairs

Zhao Dazun, Beijing Institute of Technology (China)

Ni Guoqiang, Chinese Optical Society (China)

Zhao Yuejin, Topical Committee of Optics, China Ordnance Society (China)

Members

Jin Weiqi, Beijing Institute of Technology (China)

Song Feijun, China Daheng Corporation (China)

Zhang Cunlin, Capital Normal University (China)

Theo Tschudi, Darmstadt University (Germany)

Kimio Tatsuno, Hitachi (Japan)

Wang Yongtian, Beijing Institute of Technology (China)

Bert Van Geest, Lambert Instruments (Netherlands)

Shi Yanyu, Kunming Institute of Physics (China)

Jun Ohta, Nara Institute of Science and Technology (Japan)

Gao Chunqing, Beijing Institute of Technology (China)

Bai Tingzhu, Beijing Institute of Technology (China)

D.E. Greenfield, RD\&P Center ORION (Russia)

S.V. Andreev, Prokhorov General Physics Institute (Russia)

Conference Chairs

Conference 662 1: Photoelectronic Imaging and Detection

Zhou Liwei, Beijing Institute of Technology (China)

Yoshui Suzuki, Hamamatsu Photonics K. K. (Japan)

D.E. Greenfield, RD\&P Center ORION (Russia)

Bai Tingzhu, Beijing Institute of Technology (China)

Conference 6622: Laser, Ultraviolet and Terahertz Technology

Horst Weber, Berlin Technical University (Germany)

Gao Chunqing, Beijing Institute of Technology (China)

Zhang Cunlin, Capital Normal University (China) 
Conference 6623: Image Processing

Zhao Dazun, Beijing Institute of Technology (China)

Francis T.S.Yu, University of Pennsylvania (USA)

Jun Ohta, Nara Institute of Science and Technology (Japan)

Conference 6624: Optoelectronic System Design, Manufacturing, and Testing

Wang Yongtian, Beijing Institute of Technology (China)

Theo Tschudi, Darmstadt University (Germany)

Kimio Tatsuno, Hitachi (Japan)

Conference 6625: Related Technology and Applications

Shi Yanyu, Kunming Institute of Physics (China)

Bert Van Geest, Lambert Instruments (Netherlands)

Jin Weiqi, Beijing Institute of Technology (China)

Secretariat

Secretaries General

An Liansheng, Beijing Institute of Technology (China)

Jie Deer, The Editorial Office of Optical Technique (China)

Liu Xunliang, Topical Committee of Opto-Electronic Technology, Chinese Optical Society (China)

Zhao Xueyan, The 8358th Institute of 3rd Research Academy,

CASIC (China)

Liu Baosheng, Beijing Optical Society (China)

Secretaries

Xia Yang, The Editorial Office of Optical Technique (China)

Gan Quan, Beijing Institute of Technology (China)

Zhao Baozhang, The Editorial Office of Optical Technique (China)

Wu Hong, Beijing Institute of Technology (China)

Board of Editing Management

Chair

Jie Deer, The Editorial Office of Optical Technique (China)

Cochairs

Liu Xunliang, Topical Committee of Opto-Electronic Technology,

Chinese Optical Society (China)

Xia Yang, The Editorial Office of Optical Technique (China)

An Liansheng, Beijing Institute of Technology (China)

Gan Quan, Beijing Institute of Technology (China) 
Members

Zhao Baozhang, The Editorial Office of Optical Technique (China) Xie Haiying, The Editorial Office of Optical Technique (China) 


\section{Introduction}

About 14 years ago, when I organized the first International Symposium on Photoelectronic Detection and Imaging (ISPDI) in 1993 at the Friendship Hotel in Beijing, the symposium was going successfully. At the closing ceremony, I expressed my hope and desire to organize the symposium in China again. This year the day came, as we had a great honor to organize the International Symposium on Photoelectronic Detection and Imaging meeting in Beijing once again. It is truly a great pleasure for us to be able to greet our fellow scientists and experts from a number of countries; and I firmly believe this meeting will be a successful international event in the field of photoelectronic detection and imaging.

The purpose of ISPDI'07 is to provide a forum for the participants to disseminate and exchange ideas and to present up-to-date comprehensive assessments of progress and developments in the field of photoelectronic imaging and detection. To this end it is very gratifying to me that we have been assembled here for an informative exchange of opinions.

Collected in these five volumes of are close to 400 papers accepted for presentation at the symposium, contributed by over 1000 authors from more than 10 countries, including China, Japan, Russia, Germany, Netherland, India, United Kingdom, United States, Italy, and South Korea. These papers cover topics such as photoelectronic imaging, photoelectronic detection, opto-electronic system design, manufacturing and testing, imaging processing, related technology and applications, as well as many other aspects. These proceedings will no doubt benefit not only the participants of this meeting but also our colleagues engaged in research and development. It is sincerely hoped that as a consequence of this meeting research and development in photoelectronic detection and imaging will be promoted, and international cooperation between scientists and engineers who share this common interest will be enhanced.

Finally, on behalf of Prof. Wang Daheng, Prof. Jin Guofan and Prof. Yu Xin, China Ordnance Society and Beijing Institute of Technology, I would like to heartily thank our sponsors and supporters for all they have done for this meeting. Thanks also to all the authors for their contribution to these proceedings; to all of the participants and friends for their interest and efforts in helping us to make this symposium possible, especially those who have traveled great distances and taken their valuable time from their very busy schedules to attend the meeting, to the advisory and organizing committees for their effective work and valuable advice; and to all the organizations and individuals concerned for their active support and assistance, especially the Editorial Office of Optical Technique for 
their tireless effort and outstanding service in the administration and preparation of the manuscripts for the proceedings. I am also grateful to the SPIE staff for their support and collaboration in publishing these volumes.

Liwei Zhou Topical Committee of Optics, China Ordnance Society 